\title{
AS REPRESENTAÇÕES DE GÊNERO E DIVERSIDADE SEXUAL NA MÍDIA INTERNET: ARTEFATO DE TRABALHO NO CONTEXTO ESCOLAR ${ }^{1}$
}

\author{
THE GENDER REPRESENTATIONS AND SEXUAL DIVERSITY \\ IN INTERNET MEDIA: WORK ARTIFACT IN THE SCHOOL CONTEXT
}

Cristina Tavares da Costa Rocha ${ }^{2}$

\begin{abstract}
RESUMO
\section{Resumo}

Este artigo apresenta parte de um módulo (de amplo projeto) relativo a representações de gênero e diversidade sexual na Internet, reconhecida esta como a maior de todas as redes que integram as novas tecnologias da informação e da comunicação (TICs) na contemporaneidade, caracterizada pela Sociedade em Rede. O projeto é intitulado "Refletindo gênero na escola: A importância de repensar conceitos e preconceitos", que visa sensibilizar profissionais da rede municipal de educação de Matinhos-PR sobre as questões de gênero e diversidade sexual no ensino fundamental. O nome fo módulo, que é o quarto e último da série do projeto como um todo, é: Gênero, diversidade sexual e mídia ${ }^{3}$. No presente artigo o enfoque dado à Internet privilegia sua recente conceituação como mídia. E, a partir desta conceituação, reforça-se a necessidade da Internet ter uma inserção mais significativa no ensino em geral, e no fundamental, em particular, como instrumento de trabalho e pesquisa para alunos/as e profissionais da educação, direcionado às reflexões sobre relações de gênero e diversidade sexual, visto que este instrumento auxilia a ampliar condições de cidadania aos indivíduos e coletividades. Da perspectiva da Internet como mídia e como artefato direcionado à Educação, são ressaltadas: 1) sua dimensão conservadora, visto que reproduz o status quo cultural vigente no sentido de permanências em relação a situações que reforçam concepções de caráter heterossexual e, em decorrência, de atitudes estereotipadas, preconceituosas, homofóbicas e discriminatórias em relação a GLBTs ${ }^{4}$; e 2) sua dimensão libertária, visto que incorpora concepções além das ainda hegemônicas heteronormativas, a exemplo de sites, matérias, imagens, sobre GLBTs. Palavras-chave:: gênero, diversidade sexual, mídia, TICs, Internet.
\end{abstract}

1 Este artigo foi apresentado e consta nos anais do VII Congresso Iberoamericano de Ciência, Tecnologia e Gênero, realizado em Havana, Cuba, de 18 a 21 de fevereiro de 2008. Integrou o Eixo Temático: Redes Científicas, TICs: Enfoques de Gênero.

2 Pesquisadora-Colaboradora do Grupo de Estudos e Pesquisas em Relações de Gênero e Tecnologia (GeTec) da Universidade Tecnológica Federal do Paraná (UTFPR). Também, Pesquisadora-Colaboradora do Instituto de Estudos de Gênero (IEG) da Universidade Federal de Santa Catarina (UFSC).

3 Este módulo foi ministrado em conjunto com outras professoras da equipe, porque além da Internet, foram focadas, também, as mídias: na imprensa escrita, no cinema, na literatura e na música, partes ministradas por elas.

4 GLBTs: sigla para gays, lésbicas, bissexuais e travestis. Alguns/mas pesquisadores/as já incorporam um T a mais nessa sigla, que seria para Transgêneros e/ou Transexuais. 


\begin{abstract}
This paper presents part of a module of a wider project related to gender representations and sexual diversity at Internet, known as the biggest of all networks which integrate the new Information and Communication Technologies (ICTs) nowadays, characterized by Network Society. The name of the project is: "Reflecting gender in school: The importance of rethinking concepts and preconcepts". It aims to sensibilize profissionals of the education municipal network of Matinhos (Paraná State) about gender questions and sexual diversity at basic teaching level. The module's name, which is the fourth and last one of the project series, is: "Genders, sexual diversity and media". The focus of this paper is the Internet and its conception as media. It is reinforced that Internet is necessary and needs to have a more influent insertion in educational area, and in the basic level in particular, as a work and research instrument to students and education profissionals, directed to reflexions on gender and sexual diversity, as this instrument helps to wide individual and collectivities citizenship conditions. From Internet perspective as media and as artefact directed to educational field, there are pointed out: 1) its conservative dimension, as it reproduces the real cultural status quo in the sense of having permanencies towards situations that reinforce conceptions of heterosexual characters and, as a consequence, stereotypical homophobic, discriminatory preconcepts and attitudes from heteronormative people in relation to $\mathrm{GLBTs}^{6}$; and 2) its libertarian dimension, as media that integrates conceptions beyond the hegemonic heteronormatives, for instance sites, news, documentaries, images, about GLBTs.
\end{abstract}

Keywords: gender, sexual diversity, media, ICTs; Internet.

\title{
A INTERNET COMO MÍDIA E ARTEFATO EDUCACIONAL
}

A Internet oferece benefícios potenciais tremendos aos usuários (alunos ou corpo docente) (...) [que] deveriam enxergá-la como uma grande experiência internacional de fluxo livre de informações e de compartilhamento de recursos (Linda HARASSIM, 2005, p. 253).

A opção mais imediata para o acesso amplo à Internet, na sociedade brasileira, está na escola (TALAHASHI, Tadao, 2000).

A Internet tem se propagado cada vez mais como um instrumento de comunicação mediada por computador (CMC) entre pessoas, comunidades e nações. Ela serve como mediadora, inclusive, entre o ser humano e o seu mundo ${ }^{7}$. Inicialmente, ela foi projetada para ser um sistema de informações (SI). A Internet começa a ser entendida como mídia com o passar do tempo, principalmente em decorrência da proliferação dos computadores pessoais (PCs) e sua interligação com redes de trabalho e de lazer ${ }^{8} \mathrm{Na}$ Internet são integradas simultaneamente várias linguagens: escrita, som, movimento, imagem, que podem resultar em um hipertexto e ser lido de forma não linear, como até então se lia em livros, revistas, etc. - da esquerda para a direita e de cima para baixo. Dentre os tipos de documentos encontrados na Internet citam-se: e-mails, blogs, chats, fóruns de debate, videoconferências, homepages. Um link faz a interconexão entre os

5 This module was assigned together with other professors whose media focus was: written press, movies, literature and music, besides Internet.

6 GLBTs means gays, lesbians, bisexuals and travestis. Some researchers already integrate one more "T" for transgenders and/or transexuals.

7 Para maiores informações sobre a Internet, enquanto Tecnologia da Informação e da Comunicação (TIC) nos Sistemas de Informação (SI), como mediadora dos indivíduos entre si e deles com o mundo, ver Jones (1995).

8 Para maiores informações sobre a história da Internet, ver Breton (1991). 
vários tipos de documentos, caso seja previamente programado ${ }^{9}$.

A rede foi a forma de estrutura que mais se adequou para essa comunicação, visto que se pode nela entrar e dela sair de qualquer ponto e se navega por ela livremente, aproveitando suas inúmeras opções de interesse disponibilizadas (CASTELLS, 2000). Ela tanto pode ser considerada uma mídia interpessoal (visto que propicia a comunicação de uma pessoa diretamente para outra pessoa, a exemplo de troca de emails pessoais, interação no $M S N^{10}$ ) quanto uma mídia de massa (visto que um/a emissor/a pode enviar a mesma mensagem a diversos/as receptores/as), a exemplo das manchetes dos jornais diários.

Embora este artigo dê prioridade às (e contribua com) reflexões direcionadas a representações de gênero e diversidade sexual na Internet, enquanto Tecnologia da Informação e da Comunicação (TIC) nos Sistemas de Informação (SI) e enquanto também artefato educacional, ressalto que a abrangência desta mídia é muito maior do que somente este recorte. A Internet é muito mais complexa do que apenas as temáticas tratadas neste artigo. Portanto, não há como nestas poucas páginas esgotar a contribuição da Internet enquanto mídia, artefato da educação e da comunicação, tendo mesmo sido entendida como um dos mais marcantes fenômenos sociais dos últimos vinte anos, a partir de sua crescente apropriação e uso (junto com outras NTICs) pelos indivíduos (CASTELLS, 2000).

A Internet tem revolucionado o mundo também em outros diversos campos do conhecimento, em especial o das ciências e, notadamente, no que se refere à construção do conhecimento e à difusão de resultados de pesquisas ${ }^{11}$ no âmbito das instituições de ensino, dos contextos acadêmicos e da sociedade como um todo ${ }^{12}$. Trata-se, sem dúvida, de novo paradigma que se estabelece e se fortifica com o passar do tempo. Quanto à difusão, em especial, há o exemplo do "Open Access" (Acesso Aberto ${ }^{13}$ ), que inclusive modifica estruturalmente a divulgação científica tradicional, datada de 1665 , baseada nos "journals" e/ou revistas acadêmicas. Em síntese, o novo paradigma do "Acesso Aberto" propõe uma ciência multilinguistica e democrática, disponibilizada e acessada gratuitamente na Internet, e vem de encontro às aspirações de parcela significativa da população no mundo da ciência, como retratam as conclusões de reuniões, como as ocorridas em Budapeste (Budapeste Open Access Initiative/BOA ${ }^{14}$ ), em Buenos Aires (Primer Encuentro Iberoamericano de Editores Cientificos ${ }^{15}$ ), em Berlim (Declaração de

9 Os significados de e-mails, blogs, chats, links, etc., podem ser encontrados no Dicionário de Informática. Há vários deles, inclusive on-line, como o da UOL. Disponível em: $<$ http://tecnologia.uol.com.br/dicionarios>.

${ }^{10}$ MSN identifica um programa denominado Messenger, que permite o intercâmbio de informações, a comunicação de uma pessoa a outra ou entre grupos reduzidos de pessoas, desde que estas sejam convidadas pelo/a emissor/a da mensagem a participar da conversa. Ou pode ser convidada por qualquer outro indivíduo do grupo, de preferência após consenso dos/as demais.

11 Que é o que faço neste artigo, ao relatar resultados de investigações levadas a efeito quanto ao uso da Internet como artefato cultural de trabalho direcionada ao ensino.

12 Dentre inúmeras possibilidades de seu uso, já há um número expressivo de redes que se formam conectando pessoas e instituições diversas locais, regionais, nacionais e internacionais, entrelaçando interesses, temas, ampliando possibilidades de reflexões, divulgando congressos, encontros, fatos, propondo e integrando ações conjuntas, a exemplo da RIMA -Red Informativa de Mujeres de Argentina- (rima-lista@tau.org.ar), de Emprendedoras en Red (info@emprendedorasenred.com.ar). No Brasil, há, também dentre inúmeras listas, a do Instituto de Estudos de Gênero (IEG) (estudosdegenero@yahoo.com.br) da Universidade Federal de Santa Catarina (UFSC), além de vários sites, blogs, fóruns de discussão, etc.

$13 \mathrm{O}$ acesso Aberto propõe abertura idiomática, destituindo o inglês como língua oficial da ciência) e a tirando a supremacia do mercado como central no campo científico. 
Berlim $^{16}$, Acesso Aberto), e em Valparaíso (Declaración de Valparaíso ${ }^{17}$ ).

No que diz respeito à educação especificamente, Benakouche (2003) afirma que “(...) é no ambiente escolar que as crianças e os adolescentes brasileiros que não dispõem de computador em casa poderão se apropriar do conhecimento digital”. Esta pesquisadora também propõe a urgência de uma melhor preparação de professores/as direcionados para o ensino fundamental e médio, através dos cursos de licenciatura, que ainda hoje carecem desse cuidado.

Aliás, uma das exitosas iniciativas direcionadas para professores/as do ensino médio foi o curso oferecido na Universidade de São Paulo (USP), através do projeto "Cidade do Conhecimento: Educar na Sociedade da Informação, 2002", coordenado por Regina Festa, na época representante para a América Latina da Cátedra Unesco, Mulher, Ciência e Tecnologia. O foco do curso foi no campo de estudos de gênero e foi denominado: "Ciência e Tecnologia: têm masculino e feminino?". Parte das atividades foi presencial e a outra parte foi desenvolvida no universo virtual, com o uso da Internet e os participantes do curso geraram um livro "on-line"18.

Uma outra iniciativa que teve êxito foi o curso "Gênero e Sexualidades na Escola”, organizado pela Secretaria Especial de Políticas para as Mulheres (SPM), Ministério da Educação (MEC), e British Council. Além da possibilidade presencial, o curso foi transmitido "on-line", possibilitando perguntas e respostas a todos/as, tornandose um espaço para reflexões, debates e discussões sobre as temáticas tratadas e a resultante articulação entre os/as envolvidos/as nesse processo de ensino-aprendizagem, com a utilização da Internet como artefato cultural-educacional.

\section{DUALIDADES NA INTERNET}

A Internet possui uma dimensão conservadora ${ }^{19}$, no sentido de dar continuidade ao que se passa no mundo presencial, visto que as mesmas situações, construções e fatos sociais e históricos são repassados para o mundo virtual on-line. Mas ela também possui, por outro lado, uma dimensão libertária ${ }^{20}$, na medida em que integra indivíduos de camadas menos favorecidas da população, através de projetos de inclusão social ${ }^{21}$, que propicia um maior empoderamento ${ }^{22}$ e senso de cidadania aos/às usuários/as da rede.

14 Disponível em: <http://bibliotecnica.upc.es/rebiun/BOA.pdf>. Acesso: 10 jul 2005.

15 Disponível em: <http://www.caicyt.gov.ar/eidec2005>. Acesso: 10 set 2005.

16 Disponível em: <http://www.geotropico.org/Berlin-1-2.pdf>. Acesso: 10 ago 2005.

17 Disponível em: <http://listas.rcp.net/pipermail/biblio/2004-February/003161.html>. Acesso: 22 jun 2005.

18 Disponível em: <http://www.cidade.usp.br/educar/monografias>.

19 Pelo seu caráter mantenedor das situações de desigualdades de toda ordem vigentes no mundo presencial, e ante a possibilidade destas situações se expandirem no virtual pelo alcance da Internet, há os que desenvolvem tecnofobia (medo das tecnologias) em relação a esta mais recente mídia, a Internet.

20 Do lado oposto dos/as que desenvolvem tecnofobia à Internet, há os/as infoentusiastas (BROWN \& DUGUID, 2000), que desenvolvem a tecnolatria (idolatria à tecnologia) (BONDER, 2002).

21 Exemplo de projeto de inclusão digital: "Digitando o Futuro", da Prefeitura Municipal de CuritibaPR. Através dele foi implantada uma rede computacional que agrega os 45 Faróis do Saber da cidade para acesso gratuito da população à Internet. Para maiores informações ver Rocha (2001).

22 No campo dos estudos de gênero (foco deste texto), o empoderamento refere-se às mulheres que têm "o poder de pensar, de conhecer, de agir livremente, de realizar seus potenciais, de ter uma eqüidade nas remunerações - trabalho igual, salário igual -, igualdade de chances; as redes feministas (e de gênero) brasileiras, vêm trabalhando neste sentido, segundo as perspectivas apontadas pela IV Conferência Mundial sobre as Mulheres, [realizada] em Beijin" (SWAIN, 2005, p.351). Ainda, Prá e Negrão (2005, p. 276) afirmam que empoderamento refere-se a "processo de aprendizados que amplia conhecimentos e informações, desenvolve potencialidades e aperfeiçoa percepções pela troca e o diálogo com outras/os, visando fortalecer capacidades, habilidades e a disposição para afirmar relações democráticas e o exercício real do poder". 
Qualquer informação pode ser colocada na Internet desde que respeitadas as mesmas regras de convivência na cultura em que se está inserido/a, mesmo porque existe o Núcleo Gestor da Internet, que regula a rede como um todo, tendo, portanto, controle geral sobre seus/as usuários/as. Giuliano (1999, p. 50) afirma que a Internet é: “(...) um espaço que surge como um local de liberdade, com promessas de emancipação, [e] parece ser atingido de todos os lados por formas de regulação. O próprio sujeito que habita o ciberespaço já traz consigo toda a regulação social a que está submetido. Em vez de discursos inovadores, as frases proferidas nos chats costumam ser clichês e estereótipos, normalmente produzidos pela mídia" (GIULIANO, 1999, p. 50).

\section{A DIMENSÃO CONSERVADORA DA INTERNET EM RELAÇÃO A GÊNERO}

A partir do interesse focado neste artigo, os exemplos da dimensão conservadora da Internet são os mais diversos sites que expõem informações, dados estatísticos, a partir de uma perspectiva centrada na heteronormatividade. São ainda, reflexões, etc. que reforçam o status quo vigente, no sentido do reforço da figura masculina como dominadora e da feminina como dominada.

\section{Internet e a exigência do "corpo perfeito".}

Dentre eles, menciono a publicidade que mostra a imagem da super modelo Gisele Bündchen usando peças de praia/piscina da Victoria's Secret ${ }^{23}$, uma das marcas de lingerie mais famosas internacionalmente. É a mídia Internet explorando uma figura feminina visando a vender as peças íntimas e/ou de praia e piscina, a um número cada vez maior de consumidoras. É também a mídia Internet reforçando a figura da mulher como longilínea, alta, magra, branca, cabelos e olhos claros. Percebe-se a exposição do corpo perfeito, modelo que tem sido imposto às mulheres, que procuram seguí-lo a todo custo, visando a se sentirem incluídas no padrão corporal de exigência atual. Ressalto, no entanto, que este é um modelo que tem sido orquestrado não apenas pela mídia, mas também pelas academias, a indústria farmacêutica e alimentícia, as clínicas de embelezamento, as de saúde e de estética feminina e, ultimamente, também masculinas, que começam a surgir.

\section{IWF: mais de 31 mil denúncias de sites de pedofilia na Internet.}

Um outro exemplo são os sites de pedofilia ${ }^{24}$ na rede. A Internet Watch Foundation (IWF) ${ }^{25}$ divulga relatório informando que o número desses sites tem crescido ultimamente, e a maioria deles está sediada nos Estados Unidos. Houve mais de 31 mil denúncias em 2006. A IWF diz ter encontrado imagens de sério abuso sexual infantil em mais de 10 mil páginas na Internet localizadas em cerca de 3 mil sites. Estes dados equivalem a um aumento de $34 \%$ em relação a 2005 .

23 Disponível no site da UOL Notícias na semana de maio de 2007.

24 A pedofilia é definida pela Secretaria Especial dos Direitos Humanos como a "atração erótica por crianças". Pode ser uma fantasia ou realizar-se concretamente através de atos sexuais com meninos e meninas (SARTORI, 2006).

25 Trata-se de uma das maiores organizações de fiscalização da pedofilia na Internet. Esta notícia está disponível em:

<http://www.bbc.co.uk/portuguese/reporterbbc/story/2007/04/070417_abusoinfantil_ir.shtml>. 


\section{"Parada Gay é "um ato de Satã".}

Dentre diversos exemplos menciono os sites que reforçam preconceitos homofóbicos, como o que mostra imagens de protesto contra Parada Gay em Jerusalém, Israel, em 21 de junho deste $a^{26}{ }^{26}$. Ou aquele onde há informações com imagens, sobre o prefeito de Moscou, que proibiu a Parada Gay pelo segundo ano consecutivo ${ }^{27}$. A proibição, segundo o governo local, está calcada na informação de que tal manifestação "viola os direitos da maioria dos moradores de Moscou que não são gays". Já em 2006 este prefeito teve a mesma atitude, alegando que a Parada Gay é "um ato de Satã". Manifestantes e ativistas contrários à realização da marcha, a exemplo de grupos neonazistas, tentaram agredir os homossexuais e 120 pessoas foram presas. ${ }^{28}$

\section{Deputado federal desagrada homossexuais.}

Um outro site dá notícia que Clodovil ${ }^{29}$ corre o risco de perder seu mandato de deputado federal por suas atitudes "preconceituosas, sexistas e homofóbicas". Isto porque não apenas desacatou as mulheres, em geral, alegando que hoje em dia elas "ficaram muito ordinárias, vulgares, cheias de silicone e trabalham deitadas e descansam em pé”; mas também porque desacatou uma deputada, alegando que "ela é tão feia que nem para puta serve". Ainda, ele desagradou os homossexuais alegando que não teria trabalhado a favor da "Frente Parlamentar pela Cidadania GLBT". ${ }^{30}$

\section{"A educação sexual induz à promiscuidade”.}

Há uma matéria no site de notícias da British Broadcasting Company (BBC), que exemplifica o reforço de posturas preconceituosas em relação à homofobia. Tratase de uma série de informações que o Presidente da Conferência Nacional dos Bispos do Brasil (CNBB) transmitiu, alegando que a educação sexual induz à promiscuidade.Com esta e outras afirmações ele reforça posição da igreja, contrária à diversidade sexual, principalmente homossexual, a partir de uma alegada heterossexualidade hegemônica, como normativa na sociedade ocidental ${ }^{31}$.

Fui perseguida por ser lésbica: Eu e minha companheira perdemos nossos empregos e fomos humilhadas.

No contexto educacional, uma notícia amplamente divulgada na mídia brasileira, incluindo a Internet, foi a história de duas professoras que foram demitidas da escola onde lecionavam, assim que tiveram seu relacionamento homossexual exposto por uma suposta amiga. Foram humilhadas pelo fato de serem lésbicas, segundo contou Carmem Silvia Geraldo, 52 anos, professora agora aposentada, moradora em Bodoquena-MS, que

26 Disponível em: <http://uol.com.br/notícias>. Acesso: 21 jun 2007.

27 Disponível em: <http://gonline.uol.com.br/site/arquivos/estatico/gnews/gnews_noticia_19471_htm>. Acesso: 16 mai 2007.

28 Atitude oposta teve o prefeito de São Paulo, Gilberto Kassab. Ele esteve presente na 11. ${ }^{\text {a Parada }}$ Gay da cidade, que reuniu mais de 3 mil pessoas, posicionando-se contra preconceitos e discriminações. A atual ministra do Turismo e ex-prefeita dessa cidade, Marta Suplicy, participou da manifestação, pregando o fim do preconceito e o respeito às diferenças.

${ }^{29}$ Famoso brasileiro estilista de moda que recentemente elegeu-se deputado federal.

30 Disponível em:<http://gonline.uol.com.br/site/arquivos/gnews_noticia_19463.htm>Acesso: 16 mai 2007.

31 Disponível em:

<http://bbc.co.uk/portuguese/reporterbbc/story/2007/05/070507_domgeraldodb.shtml>. 
lecionava para crianças de $1^{\mathrm{a}}$. à $4^{\mathrm{a}}$. séries. Sua companheira lecionava Língua Portuguesa para jovens de $5^{\text {a }}$ a 8 a . séries. Carmen Silvia disse: "Fiquei arrasada. Eu tinha planejado a minha aposentadoria pra dezembro. Queria fazer uma festa, convidar os colegas. Em vez disso, nem pude me despedir das minhas crianças. Saí da reunião direto para o carro que me levou à Secretaria da Educação, como se fosse uma criminosa. E chorei. Chorei durante as mais de duas horas do caminho". ${ }^{32} \mathrm{Na}$ Internet, inclusive, foi aberto um fórum "Quem você acha que está com a razão?"33 para debater este fato, visto que o prefeito da cidade divulgou na íntegra uma carta expondo o real motivo da demissão das duas professoras, que seria "[falta de] profissionalismo das professoras, isto é, o senso de responsabilidade na formação educacional de seres em formação".

\section{A DIMENSÃO LIBERTÁRIA DA INTERNET EM RELAÇÃO A GÊNERO}

Dentre diversos exemplos de seu caráter libertário, podem ser citados sites que tratam da homossexualidade, das questões das comunidades GLBTs, desconstruindo, dessa forma, posturas e abordagens homofóbicas, além de estereótipos denunciadores de atitudes rígidas construídas a partir de uma concepção da hetenormatividade, em relação a aberturas quanto a possibilidades de diversidade sexual. Há narrativas de aceitação quanto às diversas sexualidades e das opções e escolhas das atividades relativas historicamente ao mundo feminino e ao mundo masculino.

\section{Meu filho trocou a chuteira pela sapatilha}

Há um site onde são expostas narrativas de uma mãe cujo filho adolescente trocou a chuteira pela sapatilha. Ela conta que o preconceito foi grande na escola e até mesmo na família, mas que seu filho não desistiu de dançar e que ela, como mãe, deu e continua a dar todo apoio para seu sucesso. O site oferece, inclusive, a possibilidade do/a usuário/a clicar com o mouse em determinado local da notícia, direcionando-o/a para um vídeo que mostra o garoto dançando com roupas de bailarino e com sapatilhas. ${ }^{34}$

Aprendi a amar minha mãe que hoje é homossexual.

Em outro espaço do mesmo site há narrativas de uma filha que diz ter aprendido a amar sua mãe superando preconceitos, porque esta estava vivendo com uma companheira há oito anos. No começo foi difícil mas, apesar dos contratempos iniciais, a família acabou aceitando e apoiando a nova relação de sua mãe. ${ }^{35}$

\footnotetext{
32 Disponível em: <http://semanais.abril.com.br/soumaiseu/edicoes/059/soumaiseumateria_263974.shtml> Acesso: 16 mai 2007. Autor: Reportagem: Daniele Zebini. Data publicação: 13:06:0̄0 18/12/2007.

${ }^{33}$ Disponível em: <http://semanais.abril.com.br/soumaiseu/edicoes/059/soumaiseumateria_263452.shtml>. Acesso: 13 dez 2007.

34 Disponível em: <http://semanais.abril.uol.com.br/sou mais eu/video/conteudo_207979.shtml> Acesso: 27 abr 2007.

35 Disponível em: <http://semanais.abril.uol.com.br/sou maiseu/edicoes/027/aberto/aventura/conteudo_233546.shtml>. Acesso: 27 abr 2007.
} 


\section{Filha homossexual de artista rebate criticas da mãe.}

Invertendo posições familiares, há nesse site, ainda, notícias sobre a filha de Gretchen (artista brasileira de TV), que rebate críticas da mãe sobre sua homossexualidade, extensivamente divulgada na mídia, inclusive na Internet.

"É preciso estar atento ao modo de vida dos alunos que pode ter pais homossexuais, que sofrem violência sexual”.

$\mathrm{Na}$ Revista Nova Escola Abril on-line, há afirmativas que há algum tempo poderiam ser consideradas temerárias por parte considerável dos indivíduos na sociedade brasileira, como a do Secretário da Educação Continuada, Alfabetização e Diversidade do Ministério da Educação, Ricardo Henriques, durante o Seminário Nacional Tecendo Redes para Educação Integral (15 a 17 de agosto de 2006), que disse: "É preciso estar atento ao modo de vida dos alunos, que podem ter pais separados ou homossexuais, que sofrem violência sexual". ${ }^{36}$ Esta afirmativa mostra que os governos estão preocupados e empenhando esforços para acabar ou pelo menos minimizar as desigualdades existentes também e inclusive relativamente à diversidade sexual e às relações de gênero na sociedade e na escola, em especial. Este empenho precisa ter em seu eixo central de atuação, a educação sexual, e esta pode e deve ter seu início já na fase do ensino fundamental (e quiçá nas fases anteriores: creches, jardins e maternal) ${ }^{37}$.

\section{"É preciso falar de sexo".}

Menciono outro espaço neste mesmo site da Revista Nova Escola Abril, no qual há informações sobre Laura Muller, com o título da matéria: "É preciso falar de sexo". Ela é jornalista e educadora sexual. Tem pós-graduação pela Sociedade Brasileira de Estudos em Sexualidade Humana. É autora do livro "500 perguntas sobre sexo" e escreve colunas sobre este assunto em revistas semanais e em portais da Internet.

Preconceito também existe nos grupos GLBTTS.

No site intitulado "portal gay de Minas"38 há diversos depoimentos de gays e lésbicas. Há, ainda, informações sobre preconceitos incorporados e externalizados por eles e elas a respeito de suas situações e visões de vida. Afirmam que as posturas preconceituosas não partem apenas das pessoas heteronormativas em relação às GLBTs (posturas estas as quais, no senso comum, parecem ser as mais visíveis e as que ocorrem em maior número), mas são encontradas também no interior das comunidades que integram a diversidade sexual representada por GLBTs.

Em relação a esta última afirmativa, gostaria de ressaltar que a subjetividade é parte integrante da construção que se faz do conhecimento. Não há como despregá-la do pensar e do viver dos indivíduos. Portanto, entendo que há olhares "plantados" pela concepção da heterossexualidade como os há pela concepção das homossexualidades (ou bissexualidade, etc...). A beleza e a riqueza da vida também está nessa dinâmica da pluralidade e diversidade cultural, incluindo a sexual. Desta maneira, qualquer das concepções que estiver em foco a partir da subjetividade que se expressa, em nada depõe

36 Disponível em: <http://www.novaescola.abril.com.br>. Acesso: 11 fev 2007.

37 Exemplo desta preocupação e do empenho governamental é este projeto que ora o GeTec/PPGTE/UTFPR leva a efeito. Vide nota 3 deste texto.

38 Disponível em:<http://www.mgm.org.br/portal>. Acesso: 26 abr 2007. 
contra as demais concepções de sexualidades, nenhuma sendo melhor ou pior, menor ou maior, do que as demais. Se há o olhar "plantado" na heterossexualidade, pode-se considerar as demais sexualidades como alternativas (claro, a partir deste olhar, do lugar de onde se fala; das formações dos indivíduos: pessoal, acadêmica, profissional, etc.). Embora se possa afirmar que as demais sexualidades são alternativas, em nenhum momento se coloca a primazia e/ou superioridade da heterossexualidade. Isso, sim, se ocorresse, seria danoso. Da mesma forma, a partir de um olhar "plantado" na transexualidade, por exemplo, esses indivíduos podem entender as demais possibilidades de sexualidade como alternativas. Enfim, o ideal seria desconstruir, inclusive, vigilâncias ideológicas, políticas, sexuais -as que partem de concepções heterossexuais e/ou as provenientes de concepções GLBTs, que ocorrem na sociedade em geral, e especialmente no âmbito do ensino e no da academia. Em síntese, o que se busca é respeitar a pluralidade das individualidades/singularidades e as subjetividades presentes na ciranda dinâmica da vida pensada e da vida de fato vivida.

\section{CONSIDERAÇÕES FINAIS}

Na avaliação deste módulo 4, que focou "gênero, diversidade sexual e mídias", houve algumas falas de participantes direcionadas ao módulo como um todo e também algumas direcionadas para a parte específica da Internet.

Sobre o curso como um todo, eis algumas avaliações recebidas dos/as participantes: "Que bom que percebi a partir deste curso que o mundo não é só homem e mulher e que a diversidade é dificil de ser entendida e aceita; porém se começarmos a nos informar sobre esta questão "nova", fica fácil de se lidar". Ainda: "Que pena que para mim, a pior coisa foi perceber que sou preconceituosa, e o melhor é perceber que estou mudando meu jeito de pensar e principalmente agir, com meus filhos e família, alunos e colegas de trabalho".

Sobre o módulo como um todo, algumas avaliações dos/as participantes estão explicitadas a seguir: "Que bom que tivemos a oportunidade de conversar, discutir $e$ pensar sobre o que chega até nós através das mídias; é interessante que o olhar a partir de uma outra perspectiva pode reestruturar toda uma visão de mundo social de interação entre a pessoas". Ou: "que bom que aprendi a analisar as imagens de uma forma mais crítica em questões de gênero". Ainda: "Fica bem clara a situação do gênero na mídia; estes assuntos já haviam sido abordados de uma maneira sutil nos outros encontros, $e$ os deste módulo serviram para completar".

Especificamente a parte sobre a mídia Internet e gênero angariou resultados frutíferos, a exemplo de pedidos de alunas/os para que fosse criado um blog objetivando dar continuidade aos assuntos tratados durante o curso, fortalecendo a integração de todos/as envolvidos/as: professores/as, alunos/as e demais profissionais do ensino, além de um aprofundamento nas reflexões das temáticas tratadas durante os encontros. Entendo que se houvesse apenas uma solicitação neste sentido, já faria a diferença e teria valido a pena falar e discutir sobre este segmento da mídia - Internet - relativamente a gênero e diversidade sexual no ensino fundamental.

Também, houve informações direcionadas a ações integradas via correio eletrônico, a exemplo de: "Que bom se pudéssemos continuar com outros projetos que venham nos ajudar, e nos comunicarmos através de nossos e-mails." 
Ou: "Que bom se pudéssemos construir uma rede (também virtual) de facilitadores, na qual estes/as pioneiros/as que tiveram o privilégio de fazer esta capacitação pudessem estar ministrando capacitações junto às comunidades. Assim, com o tempo esta temática não será mais vista como um fator de exclusão social."

Enfim, o curso como um todo teve resultados considerados de excelência.

E a mídia Internet tem se revelado importante espaço social e cultural onde as relações de gênero e de diversidade sexual têm sido representadas, através da exploração de suas dimensões libertária e conservadora. Tem, também, se revelado importante artefato no campo da educação. Portanto, reforça-se a necessidade de sua inserção mais significativa no ensino em geral, e no fundamental, em particular, como instrumento de trabalho e pesquisa para alunos/as e profissionais da educação, direcionado às reflexões sobre relações de gênero e diversidade sexual, instrumento este que auxilia a ampliar condições de cidadania.

Mesmo que a Internet não esteja sendo utilizada em todas as suas possibilidades e potencialidades por professoras/es e demais profissionais da rede municipal de ensino de Matinhos-PR, que são as/os alunas/os do curso em foco neste artigo, entende-se que deve ser um segmento a fazer parte integrante do módulo Gêneros, diversidade sexual e mídias, por diversos motivos. Dentre eles, que esta mídia tem sido cada vez mais incorporada nas escolas, em seus variados níveis de ensino, como mais uma ferramenta disponibilizada nos dias atuais visando principalmente a facilitar a vida de estudantes e profissionais da educação ${ }^{39}$. Assim letradas/os no uso dessa mídia, ampliam-se as possibilidades de afirmação inclusive no que se refere ao exercício dos direitos de cidadania dos indivíduos, reforçando seu empoderamento pessoal e coletivo para a construção de um mundo melhor e mais igualitário em todos os sentidos, e inclusive em relação às questões de gênero. Em síntese, a não apropriação e a não incorporação da mídia Internet nas práticas do dia-a-dia nos sistemas de ensino, desde o fundamental, significam a exclusão digital-social de parcela importante da população, visto estar-se no eixo central da formação pessoal e profissional dos cidadãos.

Entendo que a Internet é um processo praticamente irreversível nos locais onde foi implantada, sendo, segundo CASTELLS (2000), um dos mais instigantes fenômenos sociais dos últimos anos.

\section{REFERÊNCIAS}

BENAKOUCHE, Tamara. A escola enquanto espaço de reprodução da exclusão digital. In: XXVII Encontro Anual da ANPOCS. Caxambu,MG, 21 a 25 out 2003.

BONDER, Gloria. Las nuevas tecnologías de información y las mujeres: Reflexiones necesarias. In: CEPAL, Série Mujer y Desarrollo. Santiago de Chile, 2002.

39 Apesar de iniciativas neste sentido, é preciso que se informe que ainda existe a seguinte situação: além de falta de estrutura física na implantação da rede Internet, Benakouche (2003) denuncia que os cursos de licenciatura continuam formando professores inabilitados para enfrentar os novos cenários integradores da sociedade e da tecnologia ("cenários sociotécnicos"). Tal situação infelizmente colabora para a exclusão digital e, portanto, social. Com a preocupação de reverter este processo de exclusão, reforço como um motivo a mais para se fortalecer este segmento "mídia Internet" no módulo 4 do curso oferecido à rede municipal de ensino de Matinhos-PR. Quanto mais letrados nessa mídia, mais os profissionais do ensino podem e devem exercer pressão junto aos órgãos governamentais para direcionar verbas e esforços para a inclusão digital-social. 
BRETON, Phillippe. História da informática. São Paulo: UNESP, 1991.

BROWN, John Seely; DUGUID, Paul. The social life of information. Boston, Massachussetts: Harvard Business School Press, 2000.

CASTELLS, Manuel. A sociedade em rede. São Paulo: Paz e Terra, 2000.

HARASSIM, Linda et. al. Redes de aprendizagem: Um guia para ensino e aprendizagem on-line. São Paulo: SENAC, 2005.

GIULIANO, R.G. Dos chats ao mundo contemporâneo. In: PORTO, S.D. (Org.). Sexo, afeto e era tecnológica. Brasília: Editora da UnB, 1999. p. 41-57.

JONES, Steven G. Cybersociety: Computer-mediated communication and community. London: Sage Publications, 1995.

PRÁ, Jussara Reis; NEGRÃO, Telia. Internet, um novo ambiente comunicativo e de empoderamento para as mulheres. In: FUNCK, S.B.; WIDHOLZER, N. Gênero em discursos da mídia. (Orgs.). Florianópolis: Ed. Mulheres; Santa Cruz do Sul: EDUNISC, 2006, p. 273-302.

ROCHA, Cristina T. da Costa. A informação via artefatos tecnológico-computacionais nas comunidades de prática: Os Faróis do Saber de Curitiba-PR. Dissertação de Mestrado. Curitiba: 2001. 168 p. (Mestrado em Tecnologia). Programa de Pós-Graduação em Tecnologia. Universidade Tecnológica Federal do Paraná.

SARTORI, Ari José. Violência contra criança e mulher, jovem ou adulta. In: SARTORI, A.J.; BRITTO, N.S. (Orgs.). Gênero na educação: Espaço para diversidade. Florianópolis: Genus, 2006, $2^{\mathrm{a}}$. ed.

SWAIN, Tânia Navarro. Mulheres, sujeitos políticos: Que diferença é esta?. In: SWAIN, T.N.; MUNIZ, Diva do Couto Gontijo Muniz. (Org.). Mulheres em Ação: Práticas discursivas, práticas políticas. Florianópolis: Ed. Mulheres; Belo Horizonte: PUC Minas, 2005, p.337-354.

TAKAHASHI, Tadao (Org.). Sociedade da Informação no Brasil: Livro Verde. Brasília: Ministério da Ciência e Tecnologia (MCT), 2000.

WOLTON, Dominique. Internet, e depois?: Uma teoria crítica das novas mídias. Tradução de Isabel Crossetti. Porto Alegre: Sulina, 2003. 